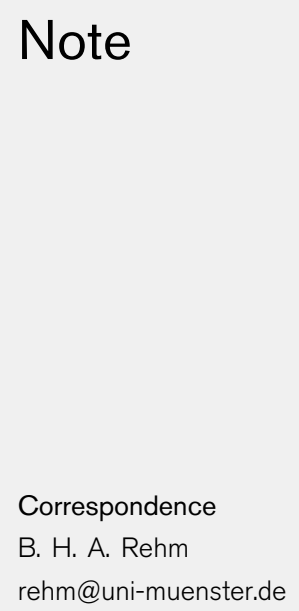

Correspondence

rehm@uni-muenster.de

\section{Sphingopyxis chilensis sp. nov., a chlorophenol-degrading bacterium that accumulates polyhydroxyalkanoate, and transfer of Sphingomonas alaskensis to Sphingopyxis alaskensis comb. nov.}

\author{
F. Godoy, ${ }^{1}$ M. Vancanneyt, ${ }^{2}$ M. Martínez, ${ }^{1}$ A. Steinbüchel, ${ }^{3}$ J. Swings ${ }^{2}$ \\ and B. H. A. Rehm ${ }^{3}$ \\ 'Departamento de Microbiología, Facultad de Ciencias Biológicas, Universidad de Concepción, \\ Casilla 160-C Concepción, Chile \\ ${ }^{2}$ BCCM/LMG Bacteria Collection, University of Ghent, K. L. Ledeganckstraat 35, B-9000 Gent, \\ Belgium \\ ${ }^{3}$ Institut für Mikrobiologie der Westfälischen, Wilhelms-Universität Münster, Corrensstrasse 3, \\ D-48149 Münster, Germany
}

\begin{abstract}
The taxonomic position of a chlorophenol-degrading bacterium, strain $\mathrm{S} 37^{\top}$, was investigated. The 16S rDNA sequence indicated that this strain belongs to the genus Sphingopyxis, exhibiting high sequence similarity to the $16 \mathrm{~S}$ rDNA sequences of Sphingomonas alaskensis LMG $18877^{\top}$ (98.8\%), Sphingopyxis macrogoltabida LMG $17324^{\top}(98 \cdot 2 \%)$, Sphingopyxis terrae IFO $15098^{\top}$ (95\%) and Sphingomonas adhaesiva GIFU $11458^{\top}(92 \%)$. These strains (except Sphingopyxis terrae IFO $15098^{\top}$, which was not investigated) and the novel isolate accumulated polyhydroxyalkanoates consisting of 3-hydroxybutyric acid and 3-hydroxyvaleric acid from glucose as carbon source. The $\mathrm{G}+\mathrm{C}$ content of the DNA of strain $\mathrm{S} 37^{\top}$ was $65.5 \mathrm{~mol} \%$. The major cellular fatty acids of this strain were octadecenoic acid $(18: 1 \omega 7 c)$, heptadecenoic acid $(17: 1 \omega 6 c)$ and hexadecanoic acid $(16: 0)$. The results of DNA-DNA hybridization experiments and its physiological characteristics clearly distinguished the novel isolate from all known Sphingopyxis species and indicated that the strain represents a novel Sphingopyxis species. Therefore, the species Sphingopyxis chilensis sp. nov. is proposed, with strain S37 ${ }^{\top}$ (=LMG $20986^{\top}$ $\left.=\mathrm{DSM} 14889^{\top}\right)$ as the type strain. The transfer of Sphingomonas alaskensis to the genus Sphingopyxis as Sphingopyxis alaskensis comb. nov. is also proposed.
\end{abstract}

The genus Sphingopyxis was created recently by Takeuchi et al. (2001). This genus was proposed as part of the splitting of the genus Sphingomonas (Yabuuchi et al., 1990), because the genus Sphingomonas represented a broad range of heterogeneous species with respect to physiology, phylogenetics and ecology. Thus, on the basis of phylogenetic evidence and some chemotaxonomic and phenotypic features that allow differentiation between the four clusters of Sphingomonas species, Takeuchi et al. (2001) proposed to emend the genus Sphingomonas (sensu stricto) and created three new genera: Sphingobium, Novosphingobium and Sphingopyxis.

Published online ahead of print on 19 September 2002 as DOI 10.1099/ijs.0.02375-0.

Abbreviation: PHA, polyhydroxyalkanoate.

The GenBank accession number for the $16 \mathrm{~S}$ rDNA sequence of strain S37 ${ }^{\top}$ is AF367204.
At the time of writing, the genus Sphingopyxis contains the species Sphingopyxis macrogoltabida and Sphingopyxis terrae. Bacteria belonging to this genus are Gram-negative, nonfermentative, aerobic, non-spore-forming, yellow-pigmented or whitish-brown, non-motile or motile, and are characterized chemotaxonomically by the presence of ubiquinone Q-10 and 2-hydroxymyristic acid (2-OH 14:0). Spermidine is the major polyamine component, sphingoglycolipids are present and the DNA G+C content is $63-65 \mathrm{~mol} \%$.

The intracellular accumulation of polyhydroxyalkanoates (PHAs) in the genus Sphingomonas has not been studied in much detail. These storage compounds are polyesters of commercial interest and represent a useful taxonomic criterion for differentiating bacterial genera (Kessler \& Palleroni, 2000). Strain $S 37^{\mathrm{T}}$, which degrades chlorophenols and is able to accumulate PHA, was isolated from sediments of a river polluted with chlorophenolic compounds (Godoy 
et al., 1999). On the basis of preliminary morphological and physiological study, strain $37^{\mathrm{T}}$ was identified as being related to Sphingomonas paucimobilis (Aranda et al., 1999; Yeber et al., 2000).

In this study, we describe the morphological, biochemical and phylogenetic characteristics of strain $\mathrm{S} 37^{\mathrm{T}}$, and also the analysis of reserve polymers of species belonging to the genera Sphingopyxis and Sphingomonas that are closely related to strain $S 37^{\mathrm{T}}$. On the basis of phenotypic data, DNA-DNA hybridization data and the results of the $16 \mathrm{~S}$ rDNA sequence analysis, we propose that strain $\mathrm{S} 37^{\mathrm{T}}$ represents a novel species of the genus Sphingopyxis, Sphingopyxis chilensis sp. nov.

\section{Bacterial strains and cultures}

Strain $\mathrm{S}^{\mathrm{T}}{ }^{\mathrm{T}}$ ( $=$ LMG $20986^{\mathrm{T}}=\mathrm{DSM} 14889^{\mathrm{T}}$ ) was isolated from the subsurface of a river (Biobío River in central Chile) polluted with chlorophenolic compounds as a 2,4,6-trichlorophenol-degrading bacterium (Godoy et al., 1999). Sphingomonas adhaesiva LMG $10922^{\mathrm{T}}$, Sphingopyxis macrogoltabida LMG $17324^{\mathrm{T}}$ and Sphingomonas alaskensis LMG $18877^{\mathrm{T}}$ were obtained from the BCCM/LMG Bacteria Collection, Gent, Belgium. All strains were grown on R2A agar (Difco) at $25^{\circ} \mathrm{C}$ unless indicated otherwise.

\section{Morphological and biochemical characterization}

The strains studied were characterized biochemically using API 20 NE test strips (bioMérieux). Phenotypic characterization using API $20 \mathrm{NE}$ strips and the comparison with other strains from the genus Sphingopyxis are summarized in Table 1. Strain $S 37^{T}$ is able to utilize glucose, mannose, maltose and fructose as sole carbon sources, whereas only weak growth was obtained with adipate, xylose and $\mathrm{N}$-acetylglucosamine as sole carbon sources (Table 1). Additionally, growth on different fatty acids was examined by culturing strain $S 37^{\mathrm{T}}$ on mineral salts medium (Schlegel et al., 1961) in the presence of $1 \%(\mathrm{w} / \mathrm{v})$ propionate, butyrate, glutarate, gluconate, valerate, hexanoate, octanoate, fumarate or decanoate at $25^{\circ} \mathrm{C}$ for $72 \mathrm{~h}$. Strain $\mathrm{S} 37^{\mathrm{T}}$ showed growth with fumarate as the sole carbon source, but was not able to grow with propionate, butyrate, glutarate, gluconate, valerate, hexanoate, octanoate or decanoate (all as sodium salts). Cells of strain $S 37^{\mathrm{T}}$ were Gram-negative, motile rods that grew aerobically. The strain produced small yellow colonies $(2 \mathrm{~mm})$ on R2A agar after 3 days incubation. The morphological, physiological and biochemical characteristics of strain $S 37^{\mathrm{T}}$ are consistent with the characteristics of the genus Sphingopyxis, as defined by Takeuchi et al. (2001) (Table 1). The phenotypic characteristics of strain $\mathrm{S} 37^{\mathrm{T}}$ allow differentiation from Sphingomonas alaskensis and Sphingopyxis macrogoltabida. Unlike these other species, strain $\mathrm{S} 37^{\mathrm{T}}$ is incapable of hydrolysing lactose ( $\beta$-galactosidase activity). Strain $\mathrm{S} 37^{\mathrm{T}}$ and Sphingopyxis macrogoltabida utilize D-mannose as a sole carbon source, whereas Sphingomonas alaskensis can not utilize this carbohydrate. In contrast to Sphingopyxis macrogoltabida, Sphingomonas
Table 1. Physiological and biochemical characteristics of strain $S 37^{\top}$ and type strains of the genera Sphingomonas and Sphingopyxis

Strains: 1, strain $\mathrm{S} 37^{\mathrm{T}}$; 2, Sphingomonas alaskensis LMG $18877^{\mathrm{T}}$; 3, Sphingopyxis macrogoltabida LMG $17324^{\mathrm{T}}$; 4, Sphingomonas adhaesiva LMG $10922^{\mathrm{T}}$. +, Positive; -, negative; (+), weakly positive; ND, not determined. The sodium salts of the respective acids were used. All strains were negative for the following characteristics: nitrate reduction, indole production, glucose acidification, arginine dihydrolase, urease, hydrolysis of gelatin and assimilation of L-arabinose, D-mannitol, citrate and phenylacetate. All strains were positive for the assimilation of glucose and malate.

\begin{tabular}{|lcccc|}
\hline Characteristic & $\mathbf{1}$ & $\mathbf{2}$ & $\mathbf{3}$ & $\mathbf{4}$ \\
\hline$\beta$-Galactosidase & - & + & + & $(+)$ \\
Hydrolysis of aesculin & + & + & + & - \\
Assimilation of: & & & & \\
$\quad$ Fructose & + & $\mathrm{ND}$ & $\mathrm{ND}$ & $\mathrm{ND}$ \\
D-Mannose & + & - & + & - \\
N-Acetylglucosamine & $(+)$ & - & - & + \\
Maltose & + & + & - & + \\
D-Gluconate & - & $\mathrm{ND}$ & $\mathrm{ND}$ & - \\
Caproate & - & - & + & - \\
Adipate & $(+)$ & $(+)$ & - & - \\
Xylose & $(+)$ & $\mathrm{ND}$ & $\mathrm{ND}$ & $\mathrm{ND}$ \\
Fumarate & + & $\mathrm{ND}$ & $\mathrm{ND}$ & $\mathrm{ND}$ \\
Propionate, butyrate, glutarate, & - & $\mathrm{ND}$ & $\mathrm{ND}$ & $\mathrm{ND}$ \\
$\quad$ valerate, hexanoate, & & & & \\
$\quad$ octanoate, decanoate & & & & \\
\hline
\end{tabular}

alaskensis and strain $\mathrm{S} 37^{\mathrm{T}}$ grow with maltose as a sole carbon source.

\section{DNA analysis}

DNA extraction, PCR amplification and purification of the PCR products were performed as described by Rainey et al. (1993). The 16S rDNA was amplified with a PCR, using a universal primer set corresponding to positions 8-27 (forward primer) and 1505-1525 (reverse primer) (Rainey et al., 1993). The PCR products were sequenced using the Taq Dye-Deoxy Terminator cycle sequencing kit (Applied Biosystems). Sequencing reactions were electrophoresed using an 4000L DNA (LI-COR) sequencer. The 16S rDNA sequence (1452 bp) of strain $S 37^{\mathrm{T}}$ was determined. Similarity values between $16 \mathrm{~S}$ rDNA sequences were obtained using internet tools as described previously (Rehm, 2001). Initial investigations on the global $16 \mathrm{~S}$ rDNA sequencebased position of the novel isolate used the ARB database (Ludwig \& Strunk, 1996). On the basis of this work, the 16S rDNA sequences were compared with the existing $16 \mathrm{~S}$ rDNA database for members of the phyletic group defined as members of the genera Sphingomonas, Novosphingobium, Sphingobium and Sphingopyxis. A phylogenetic tree was constructed as described previously (Hezayen et al., 2001; Rehm, 2001). A preliminary comparison against the GenBank database indicated that the strain is closely related 


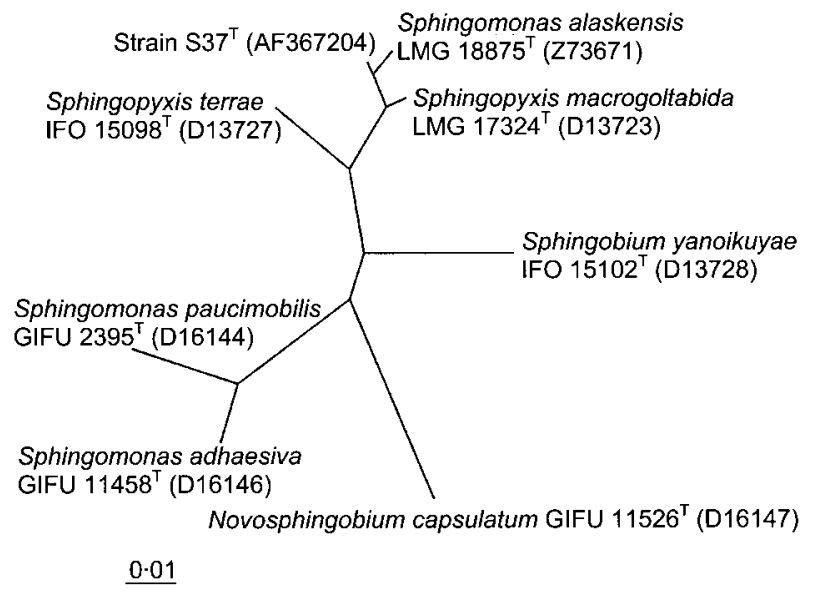

Fig. 1. Phylogenetic analysis of $16 \mathrm{~S}$ rDNA sequences of the novel isolate strain $S 37^{\top}$ and selected Sphingomonas and Sphingopyxis species as well as the type species of the genera Sphingobium and Novosphingobium. The tree was constructed by using the neighbour-joining method. Bar, 0.01 expected changes per site.

to members of the genera Sphingopyxis and Sphingomonas. The sequence of strain $S 37^{\mathrm{T}}$ showed high similarity to sequences of Sphingomonas alaskensis LMG $18877^{\mathrm{T}}(98 \cdot 8 \%)$ and Sphingopyxis macrogoltabida LMG $17324^{\mathrm{T}}(98 \cdot 2 \%)$. Similarities of 92 and $95 \%$ were found to the $16 \mathrm{~S}$ rDNA sequences of Sphingomonas adhaesiva GIFU $11458^{\mathrm{T}}$ and Sphingopyxis terrae IFO $15098^{\mathrm{T}}$, respectively. Construction of a $16 \mathrm{~S} \mathrm{rDNA}$ sequence-based phylogenetic tree indicated a phylogenetic position between Sphingomonas alaskensis and Sphingopyxis macrogoltabida (Fig. 1). For DNA base composition and DNA-DNA hybridization, cells were grown on trypticase soy agar (TSA; BBL) for $24 \mathrm{~h}$ at $28^{\circ} \mathrm{C}$. Isolation of genomic DNA and spectrophotometric determination of the $\mathrm{G}+\mathrm{C}$ content were carried out according to Vancanneyt et al. (2001). The G+C content of the genomic DNA of strain $\mathrm{S} 37^{\mathrm{T}}$ was $65 \cdot 5 \mathrm{~mol} \%$. This value is within the range observed for members of the genus Sphingopyxis (Yabuuchi et al., 1990; Takeuchi et al., 2001). DNA-DNA hybridization was carried out by fluorometric hybridization in microdilution wells using biotinylated DNA (Ezaki et al., 1989). For the fluorescence measurements, an HTS7000 Bio Assay reader (Perkin-Elmer) was used. The hybridization temperature was $52^{\circ} \mathrm{C}$. The DNA-DNA reassociation values between strain $S 37^{\mathrm{T}}$ and Sphingomonas alaskensis LMG $18877^{\mathrm{T}}$ and Sphingopyxis macrogoltabida LMG $17324^{\mathrm{T}}$ were respectively 50 and $38 \%$. These values are below the threshold value (approx. $70 \%$ ) for possible relatedness at the species level (Wayne et al., 1987).

\section{Cellular fatty acids}

Cultures were grown on TSA for $24 \mathrm{~h}$ at $28^{\circ} \mathrm{C}$. Fatty acids were extracted, separated and identified according to the
Microbial Identification System as described previously (Vandamme et al., 1992). The whole-cell fatty acid compositions of strain $S 37^{\mathrm{T}}$ and related Sphingopyxis reference strains are given in Table 2 . The major whole-cell fatty acids in strain $S 37^{\mathrm{T}}$ were octadecenoic acid $(18: 1 \omega 7 c)$, heptadecenoic acid $(17: 1 \omega 6 c)$, hexadecanoic acid $(16: 0)$ and summed feature 4 (see Table 2). Minor amounts of the 2-hydroxy fatty acids 14:0 2-OH, 15:0 2-OH and 16:0 $2-\mathrm{OH}$ were also present. The absence of $3-\mathrm{OH}$ fatty acids and the presence of 2-OH myristic acid, hexadecenoic acid $(16: 1 \omega 5 c)$ and octadecenoic acid $(18: 1 \omega 7 c)$ as the major fatty acids and octadecenoic acid $(18: 1 \omega 7 c 11$-methyl) as a minor fatty acid in strain $S 37^{\mathrm{T}}$ are features characteristic of members of the genus Sphingopyxis (Table 2).

\section{Analysis of PHA}

To promote accumulation of PHA, strain $S 37^{\mathrm{T}}$ and the type strains of Sphingomonas adhaesiva, Sphingopyxis macrogoltabida and Sphingomonas alaskensis were cultivated in mineral salts medium (Schlegel et al., 1961) containing $0.05 \%(\mathrm{w} / \mathrm{v}) \mathrm{NH}_{4} \mathrm{Cl}$ and $0.1 \mathrm{M}$ glucose at $25^{\circ} \mathrm{C}$. For analysis of PHA, $5 \mathrm{mg}$ lyophilized cells was subjected to methanolysis in the presence of a solution containing $1 \mathrm{ml}$ chloroform, $0.85 \mathrm{ml}$ methanol and $0.15 \mathrm{ml}$ sulfuric acid for $5 \mathrm{~h}$ at $100^{\circ} \mathrm{C}$. The resulting methyl esters were analysed

Table 2. Major fatty acids of strain $S 37^{\top}$ and related reference strains

Strains: 1, strain $\mathrm{S} 37^{\mathrm{T}}$; 2, Sphingomonas alaskensis LMG $18877^{\mathrm{T}}$; 3, Sphingopyxis macrogoltabida LMG $17324^{\mathrm{T}}$; 4, Sphingomonas paucimobilis LMG $1227^{\mathrm{T}}$. Tr, Trace (less than $1.0 \%$ ); ND, not detected.

\begin{tabular}{|lrrrr|}
\hline Compound & $\mathbf{1}$ & $\mathbf{2}$ & $\mathbf{3}$ & $\mathbf{4}$ \\
\hline Saturated fatty acids & & & & \\
$14: 0$ & $\mathrm{Tr}$ & $\mathrm{Tr}$ & $\mathrm{Tr}$ & 1 \\
$15: 0$ & 1 & 3 & $\mathrm{ND}$ & $\mathrm{ND}$ \\
$16: 0$ & 9 & 7 & 13 & 7 \\
$17: 0$ & 1 & 3 & $\mathrm{ND}$ & $\mathrm{ND}$ \\
Unsaturated fatty acids & & & & \\
$16: 1 \omega 5 c$ & 1 & 1 & 2 & $\mathrm{Tr}$ \\
$17: 1 \omega 6 c$ & 18 & 33 & $\mathrm{Tr}$ & 3 \\
$17: 1 \omega 8 c$ & 3 & 8 & $\mathrm{ND}$ & $\mathrm{ND}$ \\
$18: 1 \omega 5 c$ & $\mathrm{Tr}$ & $\mathrm{Tr}$ & $\mathrm{Tr}$ & 4 \\
$18: 1 \omega 7 c$ & 34 & 27 & 42 & 73 \\
$18: 1 \omega 7 c 11-$-methyl & 2 & 1 & 1 & $\mathrm{ND}$ \\
Hydroxy fatty acids & & & & \\
$14: 02-\mathrm{OH}$ & 4 & 1 & 3 & 9 \\
$15: 02-\mathrm{OH}$ & 4 & 5 & $\mathrm{ND}$ & $\mathrm{ND}$ \\
$16: 0$ 2-OH & 2 & 1 & 2 & $\mathrm{ND}$ \\
Summed feature $4 *$ & 18 & 8 & 35 & 3 \\
\hline
\end{tabular}

${ }^{\star}$ Represents one or more of the following fatty acids, which could not be separated by the Microbial Identification System: 15:0 iso

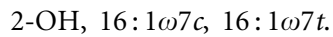


by GC (Agilent 6850 series GC system) (Brandl et al., 1988). For qualitative analysis of methyl esters, a coupled GC/MS analysis was performed using an HP 6890 gas chromatograph with a model 5973 mass-selective detector (Hewlett Packard). The mass spectra obtained were compared with the NIST '98 mass spectrum library with the Windows Search program (version 1.6; National Institute of Standards and Technology, US Department of Commerce). Experiments with strain $\mathrm{S} 37^{\mathrm{T}}$, Sphingomonas adhaesiva, Sphingopyxis macrogoltabida and Sphingomonas alaskensis cultivated on mineral medium with $0 \cdot 1 \mathrm{M}$ glucose showed that these strains accumulated PHAs consisting of 3-hydroxybutyric acid and 3-hydroxyvaleric acid (Table 3). The amount of PHA accumulated was variable among the species studied. The strongest PHA accumulation was obtained with Sphingopyxis macrogoltabida, in which it contributed $70 \cdot 2 \%$ of cellular dry weight. Sphingomonas alaskensis and strain $\mathrm{S} 37^{\mathrm{T}}$ accumulated similar amounts, PHAs contributing $26 \cdot 0$ and $24 \cdot 3 \%$ of cellular dry weight, respectively, whereas PHA accumulation in Sphingomonas adhaesiva contributed only $2.9 \%$ of cellular dry weight. Except for Sphingomonas adhaesiva, the major constituent of the PHA was 3-hydroxybutyric acid (range 97-2-99 mol\%), and 3-hydroxyvaleric acid was the minor constituent (range $0 \cdot 9-2 \cdot 8 \mathrm{~mol} \%$ ).

According to the classification proposed by Takeuchi et al. (2001) and the phylogenetic and phenotypic description given by Vancanneyt et al. (2001), Sphingomonas alaskensis should be reclassified in the genus Sphingopyxis. Phylogenetic data from the present study (Fig. 1) confirm this. We therefore propose the reclassification of Sphingomonas alaskensis within the genus Sphingopyxis as Sphingopyxis alaskensis comb. nov. This polyphasic study also clearly demonstrates that strain $S 37^{\mathrm{T}}$ represents a novel species within the genus Sphingopyxis, for which we propose the name Sphingopyxis chilensis sp. nov.

Table 3. Composition of PHAs isolated after cultivation on mineral medium with $0.1 \mathrm{M}$ glucose

3HB, 3-Hydroxybutyric acid; 3HV, 3-hydroxyvaleric acid.

\begin{tabular}{|lccc|}
\hline Strain & $\begin{array}{c}\text { PHA content } \\
(\%)^{*}\end{array}$ & \multicolumn{2}{c|}{$\begin{array}{c}\text { PHA composition } \\
(\mathbf{m o l} \%)\end{array}$} \\
\cline { 3 - 4 } & & 3HB & 3HV \\
\hline $\begin{array}{l}\text { Strain S37 } \\
\text { Sphingomonas } \\
\text { adhaesiva }\end{array}$ & $24 \cdot 3$ & $97 \cdot 2$ & $2 \cdot 8$ \\
$\quad$ LMG 10922 & & $66 \cdot 7$ & $33 \cdot 2$ \\
Sphingopyxis & & & \\
$\quad \begin{array}{l}\text { macrogoltabida } \\
\text { LMG 17324 }\end{array}$ & $70 \cdot 2$ & $99 \cdot 1$ & $0 \cdot 9$ \\
Sphingomonas & & & \\
$\quad \begin{array}{l}\mathrm{T} \\
\text { alaskensis }\end{array}$ & $26 \cdot 0$ & $98 \cdot 1$ & $1 \cdot 9$ \\
LMG 18877 & & & \\
\hline
\end{tabular}

*Total PHAs as percentage $(\mathrm{w} / \mathrm{w})$ of cellular dry weight.

\section{Description of Sphingopyxis alaskensis comb.} nov.

Basonym: Sphingomonas alaskensis Vancanneyt et al. 2001.

The description of this species is given by Vancanneyt et al. (2001). The type strain is strain RB2256 ${ }^{\mathrm{T}}$ (=CCUG $45028^{\mathrm{T}}=$ CIP $106977^{\mathrm{T}}=$ DSM $13593^{\mathrm{T}}=$ LMG $\left.18877^{\mathrm{T}}\right)$.

\section{Description of Sphingopyxis chilensis sp. nov.}

Sphingopyxis chilensis (chi.len'sis. N.L. adj. chilensis referring to Chile, where the type strain was isolated).

Cells are Gram-negative, motile, non-sporulating rods. Colonies are circular, low and convex with entire margins, yellow and $2 \mathrm{~mm}$ in diameter after 3 days incubation. The following enzyme activities are present: catalase, oxidase, hydrolysis of aesculin. No reactions are obtained for urease, production of indole, arginine dihydrolase, reduction of nitrate, hydrolysis of gelatin or lactose utilization. Glucose, D-mannose, maltose, malate and fumarate are assimilated. The following compounds are not assimilated: L-arabinose, D-mannitol, $\mathrm{N}$-acetylglucosamine, caprate, citrate, phenylacetate, propionate, butyrate, glutarate, gluconate, valerate, hexanoate, octanoate and decanoate. The major fatty acids are $18: 1 \omega 7 c, 17: 1 \omega 6 c, 16: 0$ and summed feature 4 ; the presence of the 2-hydroxy fatty acids 14:0 2-OH, 15:0 $2-\mathrm{OH}$ and $16: 02-\mathrm{OH}$ is characteristic. The $\mathrm{G}+\mathrm{C}$ content is $65.5 \mathrm{~mol} \%$. PHAs consisting of 3-hydroxybutyric acid and 3-hydroxyvaleric acid are accumulated in the presence of glucose as carbon source.

The type strain is $337^{\mathrm{T}}\left(=\mathrm{LMG} 20986^{\mathrm{T}}=\mathrm{DSM} 14889^{\mathrm{T}}\right)$, isolated from superficial sediment of a river contaminated with chlorophenolic compounds in Concepción, Chile.

\section{Acknowledgements}

We thank C. Snauwaert and A. A. Amara for excellent technical assistance.

\section{References}

Aranda, C., Godoy, F., González, B., Homo, J. \& Martínez, M. (1999). Effects of glucose and phenylalanine upon 2,4,6-trichlorophenol degradation by Pseudomonas paucimobilis S37 $7^{\mathrm{T}}$ cells in non-growth state. Microbios 100, 73-82.

Brandl, H., Gross, R. A., Lenz, R. W. \& Fuller, R. C. (1988). Pseudomonas oleovorans as a source of poly( $\beta$-hydroxyalkanoates) for potential applications as biodegradable polyester. Appl Environ Microbiol 54, 1977-1982.

Ezaki, T., Hashimoto, Y. \& Yabuuchi, E. (1989). Fluorometric deoxyribonucleic acid-deoxyribonucleic acid hybridization in microdilution wells as an alternative to membrane filter hybridization in which radioisotopes are used to determine genetic relatedness among bacterial strains. Int J Syst Bacteriol 39, 224-229.

Godoy, F., Zenteno, P., Cerda, F., González, B. \& Martínez, M. (1999). Tolerance to trichlorophenols in microorganism from pristine and polluted zone of the Biobío river (central Chile). Chemosphere 38, 655-662. 
Hezayen, F. F., Rehm, B. H. A., Tindall, B. J. \& Steinbüchel, A. (2001). Transfer of Natrialba asiatica B1T to Natrialba taiwanensis sp. nov. and description of Natrialba aegyptiaca sp. nov., a novel extremely halophilic, aerobic, non-pigmented member of the Archaea from Egypt that produces extracellular poly(glutamic acid). Int J Syst Evol Microbiol 51, 1133-1142.

Kessler, B. \& Palleroni, N. J. (2000). Taxonomic implications of synthesis of poly- $\beta$-hydroxybutyrate and other poly- $\beta$ hydroxyalkanoates by aerobic pseudomonads. Int $J$ Syst Evol Microbiol 50, 711-713.

Ludwig, W. \& Strunk, O. (1996). ARB: a software environment for sequence data. Munich: Technische Universität München. http:// www.mikro.biologie.tu-muenchen.de/

Rainey, F. A. \& Stackebrandt, E. (1993). 16S rDNA analysis reveals phylogenetic diversity among the polysaccharolytic clostridia. FEMS Microbiol Lett 113, 125-128.

Rehm, B. H. A. (2001). Bioinformatic tools for DNA/protein sequence analysis, functional assignment of genes and protein classification. Appl Microbiol Biotechnol 57, 579-592.

Schlegel, H. G., Kaltwasser, H. \& Gottschalk, G. (1961). Ein Submersverfahren zur Kultur wasserstoffoxidierender Bakterien: Wachstumsphysiologische Untersuchungen. Arch Mikrobiol 38, 209-222.

Takeuchi, M., Hamana, K. \& Hiraishi, A. (2001). Proposal of the genus Sphingomonas sensu stricto and three new genera, Sphingobium,
Novosphingobium and Sphingopyxis, on the basis of phylogenetic and chemotaxonomic analyses. Int J Syst Evol Microbiol 51, 1405-1417.

Vancanneyt, M., Schut, F., Snauwaert, C., Goris, J., Swings, J. \& Gottschal, J. C. (2001). Sphingomonas alaskensis sp. nov., a dominant bacterium from a marine oligotrophic environment. Int J Syst Evol Microbiol 51, 73-79.

Vandamme, P., Vancanneyt, M., Pot, B. \& 10 other authors (1992). Polyphasic taxonomic study of the emended genus Arcobacter with Arcobacter butzleri comb. nov. and Arcobacter skirrowii sp. nov., an aerotolerant bacterium isolated from veterinary specimens. Int J Syst Bacteriol 42, 344-356.

Wayne, L. G., Brenner, D. J., Colwell, R. R. \& 9 other authors (1987). International Committee on Systematic Bacteriology. Report of the ad hoc committee on reconciliation of approaches to bacterial systematics. Int J Syst Bacteriol 37, 463-464.

Yabuuchi, E., Yano, I., Oyaizu, H., Hashimoto, Y., Ezaki, T. \& Yamamoto, H. (1990). Proposals of Sphingomonas paucimobilis gen. nov. and comb. nov., Sphingomonas parapaucimobilis sp. nov., Sphingomonas yanoikuyae sp. nov., Sphingomonas adhaesiva sp. nov., Sphingomonas capsulata comb. nov., and two genospecies of the genus Sphingomonas. Microbiol Immunol 34, 99-119.

Yeber, M. C., Freer, J., Martínez, M. \& Mansilla, H. D. (2000). Bacterial response to photocatalytic degradation of 6-chlorovanillin. Chemosphere 41, 1257-1261. 